\title{
ĐÁNH GIÁ NGUYÊN NHÂN CHUYỂN MỔ MỞ TRONG PHẪU THUẬT NỘI SOI CẮT THÙY PHỔI
}

\author{
Nguyễn Hoàng Bình*, Vũ Hũu Vĩnh *
}

\section{TÓM TẮT:}

Trong thời gian từ 1/2013 đến 12/2016, chúng tôi đã PTNS cắt thùy phổi cho 134 bệnh nhân. Giới: 48 nữ, 86 nam. Tuổi trung bình là 55.3 .

Trong đó: bệnh lành tính: 42 bệnh nhân, trong đó u lao nhiều nhất: $17.4 \%$. Bệnh lý ác tính: 92 bệnh nhân, ung thư phổi nguyên phát: 88 bệnh nhân $(65.7 \%)$, ung thư phổi thứ phát: 4 bệnh nhân (2.9\%). Thời gian phẫu thuật trung bình: 3.34 giờ. Lượng máu mất trung bình: $82.1 \mathrm{ml}$. Tất cả bệnh nhân ra viện tốt, không có tử vong. Thời gian nằm viện sau phẫu thuật trung bình: 4.9 ngày. Chảy máu sau phẫu thuật: 1 bệnh nhân $(0.7 \%)$

Chuyển mổ mở: 8 bệnh nhân $(5.9 \%)$, trong đó 5 bệnh nhân do chảy máu khi bóc tách mạch máu, 3 bệnh nhân do hạch dính sát mạch máu, không bóc tách được. PTNS cắt thùy phổi an toàn, hiệu quả được chỉ định trong các bệnh lý phổi, bệnh nhân được chuyển mổ mở do chảy máu hay do hạch dính động mạch thùy phổi. Trong các yếu tố rãnh liên thùy không hoàn toàn, thùy trên phổi làm tăng nguy cơ chuyển phẫu thuật mở, cần chú ý khi phẫu thuật.

Tù khóa: PTNS cắt thùy phổi

\section{SUMMARY}

EVALUATING REASONS FOR

CONVERSION DURING THORACOSCOPIC

\section{LOBECTOMY}

During 4 years (1/2013-12/2015), 134 patients were opwrated thoracoscopic lobectomy. Males: 86, females: 48. Mean age: 55.3. Benign disease: 42, tuberculous tumor: 17,4\%; lung cancer: $88(65.7 \%)$, there were 4 patients metastasis to lung $(2.9 \%)$.

Mean operative time: 3. 34 hour. Mean intra-operative blood loss: $82.1 \mathrm{ml}$. Mean length of hospital stay: 4.9 days

134 patients were discharged safely. Complication: $1(0.7 \%)$ patients bleeding after operation. There werer 8 patients: conversion to open operation due to adhesive lymph nodes or injury of pulmonary artery. Thoracoscopic lobectomy is good and safety procedure. Adhesive lymph nodes and bleeding from injury of pulmonary artery during dissection are main reason for conversion. Incomplete fissure, adhesive lymph node, upper lobe are high risk factor for conversion.

Key word: thoracoscopic lobectomy.

\section{I. ĐẶT VẤN ĐỀ}

Với sự phát triển của các dụng cụ, phương tiện nội soi lồng ngực, gây mê hồi sức, phẫu thuật nội soi lồng ngực đã phát triển mạnh mẽ trong 2 thập kỷ gần đây. Phẫu thuật nội soi cắt thùy phổi (PTNS) được thực hiện đầu tiên vào những năm đầu của thập niên 1990. Trong giai đoạn đầu, PTNS cắt thùy phổi được thực hiện chủ yếu đối với các bệnh phổi lành tính hay ung thư phổi giai đoạn sớm. PTNS cắt thùy phổi đã cho thấy có thể thực hiện khả thi, an toàn có hiệu quả và có nhiều ưu điểm so với phẫu thuật mổ mở như: giảm đau sau mổ, ít suy giảm chức năng hô hấp sau mổ. Tuy nhiên vẫn còn một tỷ lệ nhất định PTNS cắt thùy phổi phải chuyển sang mổ mở. Hiện nay, vẫn còn nhiều tranh cãi về tính an toàn, sự khó khăn của PTNS cắt thùy phổi. Vấn đề được đặt ra ở đây là yếu tố nào làm tăng nguy cơ thất bại của phẫu thuật, phải chuyển mổ mở.[1,4]

* Khoa Ngoại Lồng Ngục, Bệnh viện Chợ Rãyy.

Ngườ chịu trách nhiệm khoa học: PGS.TS. Vũ Hũu Vĩnh

Ngày nhận bài: 01/05/2018 - Ngày Cho Phép Đăng: 20/05/2018

Phản Biện Khoa học: GS.TS. Bùi Đức Phú

PGS.TS. Đặng Ngọc Hùng 
Vì vậy chúng tôi tiến hành nghiên cứu này để đánh giá những nguyên, các yếu tố ảnh hưởng đến khả năng chuyển mổ mở trong PTNS cắt thùy phổi, nhằm giúp cho các phẫu thuật viên phẫu thuật an toàn hơn.

\section{II. ĐỐI TƯợNG VÀ PHƯƠNG PHÁP}

\section{1. Đối tượng:}

Tất cả bệnh nhân bệnh lý phổi có chỉ định phẫu thuật cắt thùy phổi, đủ điều kiện phẫu thuật và gây mê nội khí quản một phổi.

U phổi lành tính: $\mathrm{u}$ lao, $\mathrm{u}$ nấm, $\mathrm{u}$ phổi harmatoma...

Bệnh phổi lành tính: dãn phế quản, phổi biệt trí, bệnh mạch máu phổi bẩm sinh

Ung thư phổi nguyên phát giai đoạn sớm, ung thư phổi thứ phát

Loại trừ: bệnh nhân không có cắt thùy phổi nội soi.

2.2. Phương pháp nghiên cứu: Tiền cứu mô tả loạt ca

\section{Phuơng pháp:}

Bệnh nhân được chụp X quang phổi, Chụp cắt lớp (CT Scan), nội soi phế quản, chức năng phổi, PET khi có chỉ định, các xét nghiệm tiền phẫu.

\section{Phương pháp phẫu thuật:}

Bệnh nhân được gây mê nội khí quản 1 phổi, nằm nghiêng. Đặt 2 - 3 trocar qua đường rạch da khoảng $1 \mathrm{~cm}$ : trong đó 1 trocar cho camera, khoang liên sườn 6 đường nách trước bên trái hay khoang liên sườn 7 sau đường nách sau bên phải, 1 trocar cho dụng cụ thao tác khoảng liên sườn 5 đường nách trước bên phải hay liên sườn 7 đường nách sau bên trái. Trocar để thao tác, thường được mở rộng $3 \mathrm{~cm}$ để thao tác khi cần thiết cũng như lấy phổi ra.

Sinh thiết lạnh trước nếu không có giải phẫu bệnh lý trước mổ.

Dùng stapler cắt phế quản, tĩnh mạch, động mạch riêng lẻ.
Lấy bệnh phẩm với túi nylon để tránh mô tiếp xúc thành ngực gây nhiễm trùng

\section{Các biến số đánh giá}

Phân tích các yếu tố: thùy phổi được cắt, dính phổi, thời gian phẫu thuật, lượng máu mất trong mổ, thời gian dẫn lưu phổi, thời gian nằm viện sau mổ.

Bệnh nhân được đánh giá mức độ đau: bệnh nhân được chia theo tiêu chuẩn sử dụng thuốc giảm đau như: mức độ 1: thuốc giảm đau paracetamol, mức độ 2: Paracetamol có sử dụng thêm thuốc kháng viêm không steroid, mức độ 3 : sử dụng hoàn toàn thuốc kháng viêm không steroid hay thuốc á phiện.

Đánh giá, ghi nhận các biến chứng như: tràn khí dưới da, suy hô hấp, mủ màng phổi, dò khí, viêm phổi, nhiễm trùng....

Đánh giá nguyên nhân chuyển mổ mở.

Định nghĩa chuyển mổ mở: là khi phẫu thuật đã được tiến hành bóc tách, cắt được động mạch hay tĩnh mạch sau đó phải chuyển mổ mở. Loại trừ những trường hợp phải chuyển mổ mở ngay từ đầu do gây mê thất bại hay do phổi quá dính không phẫu thuật được. Phân tích các yếu tố ảnh hưởng đến chuyển mổ mở.

Số liệu được thống kê và phân tích dựa phần mềm SPSS 22

\section{KẾT QUẢ}

Trong thời gian từ $1 / 2013$ - 12/2015, có 134 bệnh nhân bệnh phổi được PTNS cắt thùy phổi tại khoa Ngoại Lồng ngực, BV Chợ Rẫy, tất cả bệnh nhân này đều có chỉ định cắt thùy phổi.

- Nam: 86 (64.1\%) Nữ: 48 (35.9\%)

- Tuổi: lớn nhất: 84 tuổi, nhỏ nhất: 23 tuổi trung bình: 55.3

- Triệu chứng lâm sàng: Ho và ho ra máu: 77 bệnh nhân (57.6\%); Đau ngực: 84 bệnh nhân $(62.5 \%)$ Viêm nhiễm (phổi, phế quản) tái đi tái lại: 10 bệnh nhân (7.6\%). 
1. Vị trí thùy phổi được phẫu thuật

\begin{tabular}{|l|c|c|}
\hline Thùy phổi & Số lượng bệnh nhân & Tỷ lệ (\%) \\
\hline Thùy trên phổi phải & 34 & 25.1 \\
\hline Thùy giữa phồi phải & 15 & 10.9 \\
\hline Thùy dưới phổi phải & 44 & 32.6 \\
\hline Thùy trên phổi trái & 12 & 8.7 \\
\hline Thùy dưới phồi trái & 29 & 21.7 \\
\hline
\end{tabular}

2. Bệnh lý phổi

\begin{tabular}{|l|c|c|}
\hline Loại bệnh & Số lượng bệnh nhân & Tỷ lệ (\%) \\
\hline U lao & 24 & 17.4 \\
\hline Dãn phế quản & 7 & 5.1 \\
\hline U nấm & 6 & 4.4 \\
\hline Hamartoma & 3 & 2.1 \\
\hline Phổi biệt lập & 1 & 0,7 \\
\hline Phình dò động tĩnh mạch thùy phổi & 1 & 0.7 \\
\hline Ung thư phổi nguyên phát & 88 & 65.7 \\
\hline Ung thư phối thứ phát & 4 & 2.9 \\
\hline
\end{tabular}

3. Thời gian phẫu thuật: trung bình 3,34 giờ Lâu nhất: 6 giờ. $\quad$ Nhanh nhất: 2.5 giờ

4. Lượng máu mất Trung bình: $82.1 \mathrm{ml}$. Nhiều nhất: $400 \mathrm{ml}$ Thấp nhất: $50 \mathrm{ml}$

5. Thời gian dẫn lưu màng phổi sau mổ: 2.17 ngày Lâu nhất: 7 ngày. Nhanh nhất: 2 ngày

6. Thời gian nằm viện trung bình sau mổ: 4.9 ngày Lâu nhất: 8 ngày. Nhanh nhất: 3 ngày

7. Giảm đau sau mổ

\begin{tabular}{|l|c|c|}
\hline Thuốc giảm đau sau mổ & Số lượng bệnh nhân & Tỷ lệ (\%) \\
\hline Mức độ 1 & 84 & 62.6 \\
\hline Mức độ 2 & 38 & 28.5 \\
\hline Mức độ 3 & 12 & 8.9 \\
\hline
\end{tabular}

- Biến chứng: không ghi nhận biến chứng trầm trọng

\begin{tabular}{|l|c|c|}
\hline Biến chứng & Số lượng bệnh nhân & Tỷ lệ (\%) \\
\hline Tràn khí dưới da & 9 & 6.7 \\
\hline Chảy máu sau mố & 1 & 0.7 \\
\hline Chảy máu trong mố & 5 & 3.7 \\
\hline Dò khí & 3 & 2.2 \\
\hline Xẹp phối & 1 & 0.7 \\
\hline Tràn khí MP sau rút dẫn lưu & 1 & 0.7 \\
\hline Không biến chứng & 114 & 85.3 \\
\hline
\end{tabular}


Chuyển mổ mở: 8 bệnh nhân: 5 do chảy máu từ nhánh động mạch phổi khi bóc tách, 3 do hạch dính vào động mạch không bóc tách được.

\begin{tabular}{|c|c|c|c|}
\hline Các yếu tố ảnh hưởng & $\begin{array}{c}\text { Nhóm PTNS hoàn } \\
\text { toàn: } n=126(\%)\end{array}$ & $\begin{array}{c}\text { Nhóm chuyển } \\
\text { mổ mở: } n=8(\%)\end{array}$ & $\mathbf{P}$ \\
\hline $\begin{array}{c}\text { Vị trí thùy phổi phẫu thuật } \\
\text { Thùy trên phải } \\
\text { Thùy giữa phải } \\
\text { Thùy dưới phải } \\
\text { Thùy trên trái } \\
\text { Thùy dưới trái }\end{array}$ & $\begin{array}{l}31(90.4 \%) \\
15(100 \%) \\
41(93.3 \%) \\
11(90.9 \%) \\
28(96.6 \%)\end{array}$ & $\begin{array}{c}3(9.6 \%) \\
0(0 \%) \\
3(6.7 \%) \\
1(9.1 \%) \\
1(3.4 \%)\end{array}$ & $\mathrm{P}=0.59$ \\
\hline $\begin{array}{l}\text { Hạch cạnh động mạch phổi } \\
\text { Không có hạch } \\
\text { Có hạch }\end{array}$ & $\begin{array}{l}43(100 \%) \\
83(91.2 \%)\end{array}$ & $\begin{array}{c}0(0 \%) \\
8(8.8 \%)\end{array}$ & $P=0.26$ \\
\hline $\begin{array}{l}\text { Bệnh lý ác tính } \\
\text { Bệnh lành tính } \\
\text { Ung thư }\end{array}$ & $\begin{array}{l}39(92.8 \%) \\
87(94.5 \%) \\
\end{array}$ & $\begin{array}{l}3(7.2 \%) \\
5(5.5 \%) \\
\end{array}$ & $P=0.64$ \\
\hline $\begin{array}{l}\text { Rãnh liên thùy } \\
\text { Không hoàn toàn } \\
\text { Hoàn toàn } \\
\end{array}$ & $\begin{array}{l}95(92.2 \%) \\
31(100 \%)\end{array}$ & $\begin{array}{c}8(7.8 \%) \\
0(0 \%)\end{array}$ & $\mathrm{P}=0.063$ \\
\hline $\begin{array}{l}\text { Phổi dính } \\
\text { Không dính } \\
\text { Phổi dính } \\
\end{array}$ & $\begin{array}{l}69(95.8 \%) \\
57(91.9 \%) \\
\end{array}$ & $\begin{array}{l}3(4.2 \%) \\
5(8.1 \%) \\
\end{array}$ & $\mathrm{P}=0.43$ \\
\hline $\begin{array}{r}\text { Kích thước } \mathbf{u} \\
\mathrm{U}<4 \mathrm{~cm} \\
\mathrm{U} \geq 4 \mathrm{~cm}\end{array}$ & $\begin{array}{l}\mathbf{n}=\mathbf{1 1 9}(\boldsymbol{\%}) \\
72(92.3 \%) \\
47(95.9 \%)\end{array}$ & $\begin{array}{l}\mathbf{n}=\mathbf{8}(\%) \\
6(7.7 \%) \\
2(4.1 \%)\end{array}$ & $\mathrm{P}=0.159$ \\
\hline
\end{tabular}

\section{BÀN LUẬN}

Những năm đầu thập niên 1990, sau khi Kirby giới thiệu ca PTNS cắt thùy phổi đầu tiên, PTNS cắt thùy phổi bắt đầu được triển khai tại các trung tâm phẫu thuật lồng ngực trên thế giới [4,5]. PTNS cắt thùy phổi lúc đầu được chỉ định áp dụng đối với các bệnh phổi lành tính có chỉ định cắt thùy, sau đó khi các phẫu thuật viên đã có nhiều kinh nghiệm, PTNS cắt thùy phổi được chỉ định cả trong ung thư phổi. PTNS cắt thùy phổi có thể thực hiện an toàn với nhiều ưu điểm như ít đau sau mổ, xuất viện sớm [1].

\section{PTNS cắt thùy phổi an toàn}

PTNS cắt thùy phổi hiện vẫn chưa được nhiều trung tâm áp dụng rộng rãi vì vẫn còn nhiều lo ngại về tính an toàn, kỹ thuật thực hiện, chi phí... Mặc dù kỹ thuật phẫu thuật, sự lựa chọn bệnh khác nhau, nhưng các nghiên cứu của các tác giả đều cho thấy PTNS cắt thùy phổi có tỷ lệ biến chứng thấp hơn hay tương đương mổ mở. Theo nghiên cứu của tác giả Mc Kenna, phẫu thuật mổ mở cắt thùy phổi: có tỷ lệ biến chứng từ $28-38 \%$, tỷ lệ tử vong $1,2-2,9 \%$, trong khi PTNS cắt thùy phổi: tỷ lệ biến chứng thay đổi từ $9-19 \%$, tỷ lệ tử vong: $0,8-1,2 \%$.[2]

Trong nghiên cứu của chúng tôi, tỷ lệ biến chứng chỉ chiếm $14.7 \%$, không có bệnh nhân tử vong.

Uu điểm của PTNS: Thời gian nằm viện ngắn, xuất viện sóm, giảm đau sau mổ

Một trong những lí do mà PTNS cắt thùy phổi được các phẫu thuật viên ưa thích hơn, dù có những khó khăn về kỹ thuật, chính là những ưu điểm của PTNS so mổ mở: đau sau mổ ít hơn, 
bệnh nhân nằm viện ngắn hơn, trở lại công việc sớm hơn, tính thẩm mỹ.

Theo nghiên cứu của Todd Demmy, bệnh nhân PTNS có số ngày nằm viện sau mổ ít hơn so bệnh nhân mổ mở (5.3 ngày so với 11.3 ngày), bệnh nhân PTNS có đường mổ nhỏ, không banh ngực nên ít đau sau mổ hơn, xuất viện sớm hơn. Hầu hết các nghiên cứu đều cho thấy, bệnh nhân PTNS giảm đau đáng kể sau mổ. Theo Daniel $\mathrm{G}$ Nicastri: $47 \%$ bệnh nhân không sử dụng thuốc giảm đau 2 tuần sau mổ, $26 \%$ sử dụng thuốc kháng viêm khôngsteroid, $22 \%$ dùng thuốc giảm đau gây nghiện khi cần, $27 \%$ dùng thuốc giảm đau gây nghiện [6].

Trong nghiên cứu của chúng tôi: Ngày nằm viện sau mổ trung bình là 4.9 ngày. Trường hợp bệnh nhân nằm viện lâu nhất là bệnh nhân bị dò khí: 8 ngày. Đa số bệnh nhân được rút dẫn lưu vào ngày hậu phẫu thứ 2 . Lượng máu mất trung bình khoảng $82.1 \mathrm{ml}$, thời gian mổ trung bình 3.34 giờ không quá lâu so với mổ mở. Thuốc giảm đau: hơn $90 \%$ dùng thuốc giảm đau mức độ I, II; chỉ có $8.9 \%$ sử dụng thuốc giảm đau mức độ III, tức thuốc giảm đau gây nghiện.

Nguyên nhân, yếu tố ảnh hưởng chuyển mổ mở

Nhiều phẫu thuật viên Lồng ngực chưa dám PTNS cắt thùy phổi mà vẫn sử dụng phẫu thuật mở để cắt thùy phổi là do lo sợ về sự an toàn của phẫu thuật. Một trong những tiêu chuẩn đánh giá sự an toàn của PTNS cắt thùy chính là tỷ lệ chuyển mổ mở. Tỷ lệ chuyển mổ mở trong PTNS cắt thùy phổi thay đổi tùy theo nghiên cứu, tỷ lệ này thay đổi từ 2-6\% [1]. Với kỹ năng, kỹ thuật kinh nghiệm phẫu thuật viên ngày càng được cải thiện, tỷ lệ chuyển mổ mở đã giảm dần từ $8 \%$ còn $5 \%$ sau 5 năm. Tuy nhiên, dù tỷ lệ thành công của PTNS ngày càng tăng dần, vẫn còn một tỷ lệ bệnh nhân phải chuyển mổ mở, điều này cũng nói lên vẫn còn một tỷ lệ bệnh nhân còn khó khăn khi thực hiện PTNS [7].
Theo Shigeki Sawada, nguyên nhân của PTNS chuyển phẫu thuật mở được chia làm hai nhóm:

1. Nhóm 1: các nguyên nhân liên quan phương pháp PTNS như: chảy máu khi bóc tách, chảy máu do staplers bị lỗi khi cắt mạch máu.

2. Nhóm 2: các nguyên nhân không liên quan PTNS như hạch dính, rãnh liên thùy không hoàn toàn, phổi dính.

Nguyên nhân thường gặp trong chuyển mổ mở nhiều nhất là chảy máu trong mổ và hạch dính, xâm lấn mạch máu không bóc tách được. Các nguyên nhân khác ít gặp hơn là do rãnh liên thùy hoàn toàn không bóc tách ĐM được, phổi dính màng phổi gây khó khăn cho phẫu thuật.

Một nguyên nhân khác chỉ định chuyển mổ mở theo một số phẫu thuật viên là khi phát hiện có hạch trung thất trong mổ, nếu có kết quả di căn hạch trong mổ nên chuyển phẫu thuật mở vì bệnh nhân ung thư phổi bị di căn N2 không thích hợp cho PTNS [7].

Trong nghiên cứu của Mc Kenna $(\mathrm{n}=251)$, có 28 bệnh nhân chuyển mổ mở $(2.5 \%)$ nguyên nhân là do chảy máu, dính phổi, kích thước u lớn, u xâm lấn thành ngực và quá giai đoạn [3].

Theo Sawada, khi có biến chứng chảy máu trong mổ, phẫu thuật viên đè bằng tăm-bông ép trước, đánh giá xem có thể kiểm soát chảy máu với PTNS không, khi chảy máu không thể kiểm soát hay khó khăn trong khâu cầm máu thì nên chuyển mổ mở.

PTNS có lợi điểm là cho phép phẫu thuật viên nhìn thấy phẫu trường được phóng đại lớn hơn, thuận lợi cho bóc tách mạch máu hay xác định những chảy máu nhỏ. Tuy nhiên, việc phải phẫu thuật trong một phẫu trường hẹp, bằng các dụng cụ nội soi khiến cho khả năng cầm máu khó khăn hơn, đòi hỏi phẫu thuật viên phải được huấn luyện, có kinh nghiệm mới tránh đưa ra quyết định chuyển mổ mở.

Mục đích của phẫu thuật là thực hiện an 
toàn và phẫu thuật cắt hoàn toàn tổn thương bệnh lý, một khi có sự cố trong phẫu thuật, nếu cố gắng PTNS có thể kéo dài thời gian và tăng nguy cơ phẫu thuật, vì vậy không nên do dự khi quyết định chuyển mổ mở [9], [7], [8].

Trong nghiên cứu của chúng tôi, có 8 trường hợp chuyển mổ mở, trong đó:

14. 5 trường hợp do chảy máu trong mổ: 3 bệnh nhân bị tổn thương ĐM phổi khi bóc tách, một bệnh nhân chảy máu do lỗi kỹ thuật dùng staplers, một bệnh nhân bị chảy máu do tổn thương TM bất thường đổ từ phân thùy đỉnh sau thùy trên vào $\mathrm{TM}$ thùy giữa, không cầm được.

15. 3 trường hợp chuyển phẫu thuật mở do hạch dính sát, xâm lấn ĐM cho thùy phổi không bóc tách được.

Phân tích các yếu tố liên quan chuyển phẫu thuật mở

\section{Vi trí thùy phổi:}

Thùy trên phổi trái là thùy phổi được chuyển phẫu thuật mở nhiều nhất, do sự khó khăn khi bóc tách mạch máu phổi so với các thùy phổi khác[7]. Vì vậy đa số phẫu thuật viên khi bắt đầu PTNS thường chọn thùy dưới hay thùy giữa để phẫu thuật hơn là thùy trên.

Trong nghiên cứu của chúng tôi, tỷ lệ chuyển mổ mở cao nhất là ở nhóm bệnh nhân được phẫu thuật cắt thùy trên $(9.6 \%$ thùy trên phải và $9.1 \%$ thùy trên trái $-\mathrm{P}>0.05$ )

\section{Kich thuoóc u:}

Trước đây, các phẫu thuật viên thường không chỉ định PTNS khi khối u $>6 \mathrm{~cm}$, khối u phổi càng lớn thường, không gian phẫu thuật càng bị hạn chế, gây khó khăn khi thao tác trong PTNS [2]. Mặt khác sự bể u khi lấy u có thể ảnh hưởng đến kết quả phẫu thuật. Tuy nhiên, với kinh nghiệm phẫu thuật của phẫu thuật viên ngày càng tăng lên, kích thước khối u được PTNS cũng ngày càng lớn hơn.

Trong nghiên cứu của chúng tôi, kích thước khối u chúng tôi phẫu thuật lớn nhất là $6 \mathrm{~cm}$, nhóm bệnh nhân có kích thước $\mathrm{u}<4 \mathrm{~cm}$ lại có tỷ lệ chuyển mổ mở cao hơn $7.7 \%$ so nhóm có $\mathrm{u}>$ $4 \mathrm{~cm}$ là $4.1 \%$, sự khác biệt không có ý nghĩa thống kê $(\mathrm{P}>0.05)$.

\section{Rãnh liên thùy}

Bệnh nhân có rãnh liện thùy không hoàn toàn, khi phẫu tích thường khó khăn hơn, dễ gây biến chứng chảy máu khi bóc tách động mạch, vì vậy nguy cơ chuyển mổ mở nhiều hơn. Ngày nay, với sự phát triển của các dụng cụ, bóc tách cầm máu như dao cắt đốt siêu âm...rãnh liên thùy chia không hoàn toàn, dù vẫn còn nguy cơ chuyển mổ mở nhưng đã không còn là chống chỉ định đối với PTNS.

Trong nghiên cứu của chúng tôi, tất cả các trường hợp chuyển mổ mở đều có rãnh liên thùy không hoàn toàn $(7.8 \%)(\mathrm{P}>0.05)$

\section{Hach canh đông mach thùy phổi}

Hách dính, xâm lấn mạch máu thường gây cản trở bóc tách mạch máu, dễ gây biến chứng chảy máu, ảnh hưởng kết quả PTNS, đặc biệt là hạch ung thư. Hiện nay, đây vẫn còn là nguyên nhân gây khó khăn, cân nhắc cho phẫu thuật viên quyết định PTNS hay mổ mở.

Trong nghiên cứu của chúng tôi, có ba trường hợp PTNS phải chuyển phẫu thuật mở, vì hạch xâm lấn, dính động mạch phổi, không bóc tách được, tất cả trường hợp chuyển mổ mở đều có hạch cạnh động mạch phổi. ( $\mathrm{P}>0.05)$

\section{Phổi dính}

Phổi dính khoang màng phổi là một trong những khó khăn cho PTNS, ngày nay phổi dính trong khoang màng phổi không còn là một chống chỉ định cho PTNS. Trong nghiên cứu của chúng tôi, tỷ lệ chuyển mổ mở ở nhóm phổi dính lại cao hơn so với nhóm phổi không dính (8.1\% so 4.2\%) nhưng không có ý nghĩa thống kê $(\mathrm{P}>0.05)$.

Bênh lýác tính.

Theo một số tác giả, bênh nhân có bệnh phổi lành tính có viêm nhiễm, có nguy cơ viêm dính, hạch dính gây biến đổi giải phẫu. Vì vậy, 
bóc tách khi PTNS khó khăn hơn, nguy cơ chuyển mổ mở cao hơn. [4]

Trong nghiên cứu chúng tôi, chúng tôi nhận thấy có tỷ lệ chuyển mổ mở ở hai nhóm bệnh nhân bệnh lành tính và ác tính là không khác biệt có ý nghĩa thống kê.(P>0.05)

\section{KẾT LUẬN}

PTNS cắt thùy phổi là phương pháp phẫu thuật an toàn, hiệu quả có nhiều ưu điểm, có thể chỉ định rộng rãi trong các bệnh phổi. Hai nguyên nhân chính thường gây chuyển mổ mở là chảy máu động mạch phổi khi bóc tách trong mổ và hạch dính động mạch phổi không bóc tách được. Thùy trên phổi và rãnh liên thùy không hoàn toàn là những yếu tố gây tăng nguy cơ chuyển mổ mở.

\section{TÀI LIỆU THAM KHẢO}

1. Scott J Swanson and Hasan F Batirel. (2002) Video-assisted thoracic surgery (VATS) resection for lung cancer. The surgical clinics of North America, p 541-561

2. Robert J Mc Kenna, Jr, MD.(2007). Anatomic pulmonary Resections by videoassisted Thoracic surgery. Advanced theraphy in thoracic surgery, p68-74

3. Robert J. McKenna Jr.(2005). VideoAssisted Thoracic Surgery for Wedge Resection, Lobectomy, and Pneumonectomy. General Thoracic Surgery, p524 -532
4. Raja M. Flores and Naveed Z. Alam (2007). Video-Assisted Thorascopic Surgery. Major Lung Resections. Difficult decision in thoracic surgery, p 140 - 146

5. Thomas J. Kirby, Brian P Priest (1994). Video assisted thoracoscopic lobectomy. Atlas of video-assisted thoracic surgery. p221-226.

6. Daniel G. Nicastri, MD, J.P. Wisnivesky, MD, Jaime Yun, MD, Cynthia Chin, MD, F.R. Dembitzer, MD and S.J Swanson, MD. Thoracoscopic lobectomy: Report on safety, discharge independence, pain, and chemotherapy tolerance. J Thorac Cardiovasc Surg 2008;135:642-7

7. Sawada S., Komori E. \& Yamashita M. (2009), "Evaluation of video-assisted thoracoscopic surgery lobectomy requiring emergency conversion to thoracotomy", European Journal of Cardio-thoracic Surgery 36, p 487-490.

8. Sihoe A. D. L. \& Yim A. P. C. (2008), "Video-assisted pulmonary resections", Pearson's Thoracic and Esophageal Surgery., 80, p 970-988.

9. Gazala S., Hunt I., Valji A., Stewart K. \& Be'dard E. L. R. (2011), "A method of assessing reasons for conversion during videoassisted thoracoscopic lobectomy", Interactive CardioVascular and Thoracic Surgery 12, $\mathrm{p}$ 962-964. 